\title{
МЕЖПОКОЛЕННАЯ КОММУНИКАЦИЯ В КОНТЕКСТЕ СОВРЕМЕННОГО ОБРАЗОВАНИЯ ЛИЧНОСТИ
}

\section{INTERGENERATIONAL COMMUNICATION IN THE CONTEXT OF MODERN PERSONAL EDUCATION}

\section{Abu-Taleb}

Summary: In the article, the author considers the communication aspect of education (interpersonal and intergroup communication, school and family communication, intra-school and intra-family communication, intergenerational communication). The author analyzes intergenerational communication from the point of view of integral education. Special attention is paid to integral education as a unique educational paradigm that corresponds to the current state of society. The author also writes about the "metaphigurative culture», comparing it with the classical types of cultures according to M. Mead.

Keywords: intergenerational communication, personality education, integral education, communicative and cognitive space, symbolic interactionism, metaphigurative culture.

\author{
Абу-Талеб Дарья Викторовна \\ Соискатель, Институт психологии творчества \\ onedeka@mail.ru
}

Аннотация: В статье автор рассматривает коммуникационный аспект образования (межличностная и межгрупповая коммуникация, коммуникация школы и семьи, внутришкольная и внутрисемейная коммуникация, межпоколенная коммуникация). Межпоколенную коммуникацию автор анализирует с точки зрения интегрального образования. Особое внимание в статье уделено интегральному образованию как уникальной образовательной парадигме, соответствующей актуальному состоянию общества. Также автор пишет о "метафигуративной культуре", сравнивая ее с классическими типами культур по М. Мид.

Ключевые слова: межпоколенная коммуникация, образование личности, интегральное образование, коммуникативно-когнитивное пространство, символический интеракционизм, метафигуративная культура.
A ктуальность темы современного образования личности обосновывается в исследованиях, относящихся к различным наукам: педагогике, психологии, социологии, культурологии, философии образования и т.д. В данной статье мы затронем коммуникационный аспект образования (межличностная и межгрупповая коммуникация, коммуникация школы и семьи, внутришкольная и внутрисемейная коммуникация). Рассмотрение межпоколенной коммуникации в контексте современного образования личности - сложная тема, требующая комплексного подхода.

Во-первых, следует понимать, что такое современное образование, которое мы называем образованием личности. Под "образованием личности" мы понимаем процесс, непрерывный по ряду значимых параметров: во времени (образование в течение всей жизни и на протяжении каждого конкретного дня), в пространстве (в том числе - в реальном и интернет-пространствах), в межличностном и внутриличностном аспектах (то есть, в поле межличностной и внутриличностной коммуникации). Мы называем такой процесс интегральным, а такой (образовательный) феномен - интегральным образованием [5]. Мы говорим об образовании личности, подчеркивая непрерывность образовательного процесса: речь идет не только и не столько об области, родственной педагогике и затрагивающей школьное (дошкольное, университетское, дополнительное и т.д.) образование, сколько об образовании личности на протяжении всей ее жизни, в интегральном единстве различных сфер ее жизни, в частности - в интегральном единстве отдельных ролей ее ролевого репертуара.

Традиционное дошкольное, школьное, университетское, специальное, дополнительное образование также претерпевает изменения по ряду значимых аспектов. В частности, можно отметить все большее "перемещение" образовательного процесса в интернет-пространство, что, во многом, влияет на характер и качество образовательного взаимодействия и результата. Отметим, что характер образовательного процесса в интернет-пространстве можно назвать интегральным: взаимодействие преподавателя (учителя) и студента (ученика) в цифровом мире происходит без соблюдения привычной субординации, где учитель и преподаватель стоят "над" учениками и студентами. Кроме того, в цифровом пространстве размываются традиционные социальные роли, поскольку учитель предстает перед учеником в разных своих социальных ролях: так, в социальных сетях ученики могут наблюдать за различными аспектами неформальной, личной жизни учителя, узнавать его личностные черты, проявленные в других, отличных от образовательного, контекстах социального взаимодействия. То же справедливо и в отношении другого вектора этой коммуникации - "учитель-ученик". Стоит отметить, что образовательные платформы не имеют привычной нам 
конфигурации аудиторий и классов, где взоры учеников обращены в сторону учителя, где все внимание учащихся сконцентрировано на учебном процессе. Дисциплинарные пространства - часть человеческой культуры. О них и пишет в своих исследованиях Мишель Фуко, предлагая их своим читателям различными и в множестве. Историческая связь с правлением и властью, соответствующего времени (эпохи), данных пространств, имеет влияние по настоящее время, как в области геополитики (различие в масштабе стратегий), так и в области культурологического наследия в виде архитектурных сооружений с их смысловым назначением (больницы, школы, храмы, церкви и т.п.). и распространено, как в межличностном так и в межгрупповом процессе коммуникации [8],[9].

Сегодня дисциплинарные пространства аудиторий сменяются виртуальными пространствами учебных комнат в zoom и других платформ, где взаимодействие участников происходит (преимущественно) на равных, а также - одновременно происходит в домашнем физическом пространстве, которое объединяет домашний и рабочий контексты социального бытия, а также может (негативный аспект) отвлекать преподавателя и учащегося от процесса обучения.

Таким образом, один из аспектов интегральности (интегрального образования) - смешение контекстов ("учебного" и "домашнего", "частного" и "публичного"). Второй аспект интегральности, замеченный выше, - интеграция виртуального и реального пространств коммуникации. Еще один значимый аспект интегральности в современном образовании (даже не называющем себя интегральным) - смешение, объединение ролей участников образовательного процесса.

Последний тезис объясним подробнее. По нашему мнению, смешение ролей неизбежно при переходе на удаленное обучение. В условиях такого перехода трансформировался традиционный ролевой репертуар еще одних участников образовательного процесса - родителей. Так, в традиционном понимании школьного образования и педагогики вообще, родители не являются прямыми участниками образовательного процесса, часто они "вынесены за скобки" учебного пространства и относятся к нему, в известной мере, только во время родительских собраний. В современном же понимании образовательного процесса, свойственного интегральному образованию, родители включены в интегральное образовательное пространство в качестве значимых участников образовательного взаимодействия. Отметим, что речь идет не о том, что родители обязаны помогать ребенку с учебой, а о налаженном канале кроссличностной коммуникации "родители-ученики-преподаватели", о транспарентности информации, циркулирующей в этом канале.
Стоит заметить, что в условиях "удаленного обучения", ассоциированных с ситуацией пандемии, родители оказались участниками образовательного процесса: невольными, "незаметными", исключенными и почти "нелегальными". Удаленное обучение не предполагает (изначально) обязательного участия родителей - как менеджеров учебного процесса, как техподдержки, как репетиторов, как тьюторов, как психологов, как воспитателей, - но предполагает его по факту. По нашему мнению, эффективный процесс удаленного обучения (в том виде, в котором мы знаем его в современной России) был бы невозможен без участия родителей. Думается, что участие родителей в "штатном" интегральном образовании должно быть другим, и должно быть предусмотрено изначально.

Выше мы упомянули о технической стороне современного образования. В том виде, в котором техника и технологии вовлечены в современное удаленное образование, техническая сторона учебного процесса превращается в дополнительный стрессовый фактор. Так, в одной семье может быть только один компьютер или планшет, разделить который между несколькими детьми (в одно и то же время) - невозможно. Устранять последствия этого стресса, как и осуществлять техническую поддержку, также приходится родителям. Таким образом, ролевой репертуар родителя принудительно "обогащается" новыми ролями, среди которых не только перечисленные выше роли тьюторов, психологов, воспитателей, техподдержки, но и роль репетитора, "домашнего преподавателя", вынужденного разбираться в темах занятий и методологии учебного процесса. Это еще один из аспектов смешения ролей, имеющий отношение не столько к парадигме интегрального образования, сколько к практике домашнего "удаленного" обучения в том виде, в котором оно сейчас существует.

Интегральный подход в образовательной системе подразумевает, что обычный урок проходит в интегративной обстановке, предполагающей размывание субординаций между учеником и педагогом, что создает такую атмосферу (пространство), в котором усвоение, запоминание, понимание дисциплины (предмета) будет происходить не в стресогенной обстановке (как сегодня это часто бывает для обеих сторон процесса (учительученик), а в обстановке интегральной субординации, где роли, отведенные каждому из участников, не имеют таких жестких и подавляющих ограничений и рамок, как при вертикальной иерархичной коммуникации. В интегральной коммуникации, горизонтальной и равной, участники одного процесса могут не только исполнять отведенные им естественные роли (учителя, ученика, воспитателя), но и меняться ролями. Так же интегративная обстановка, лежащая в основе интегрально подхода, предусматривает отыгрывание ролевого репертуара, включающего в себя множественность социальных ро- 
лей, взятых из концепции мультиролевого потенциала любого субъекта на примере модели мультиролевой личности [6],[3]. В основу концепции мультиролевой личности заложена феноменология субличностей К.- Г. Юнга [11], Р. Ассаджиоли [1], Хел Стоуна и Сидры Уинкельман [7], Ричард К. Шварца [10], теория М. Боуэна (1978) о “дифференциации Я”. [12]

Из написанного выше видим, что аспект межпоколенной коммуникации в интегральном образовании является одним из ключевых. Таким образом, в данной статье следует также уделить внимание вопросу межпоколенной коммуникации в интегральном образовании. Это связано, в частности, с тем, что образование в современном мире распространяется на всю жизнь человека, возраст учащегося может быть, фактически, любым - от детского до старшего, что приводит к ситуациям, где учебные группы - разновозрастные, и преподаватель может быть младше большинства учащихся. Особенностью межпоколенного взаимодействия вообще (и межпоколенной коммуникации - в частности) становится, таким образом, размывание границ поколений - как поколений условных "студентов" и "преподавателей". Также стоит отметить размывание возрастных границ в рамках поколения родителей - так, родители детей одного и того же возраста могут относиться к разным поколениям, что также формирует еще один аспект межпоколенного взаимодействия в интегральном образовании.

Особенность современного информационного общества состоит, среди прочего, в его префигуративности (по М. Мид [4]). Префигуративную культуру отличает то, что представители старших поколений (взрослые) перенимают знания у детей, поскольку в развитых обществах среда и знания о ней меняются так быстро, что дети (находясь в процессе социализации) схватывают знания о ней (и отдельных особенностях ее проявления) гораздо быстрее, чем взрослые. Особенно это касается информационной среды, взаимодействию в которой, как и техническим особенностям работы которой, - дети обучаются гораздо быстрее, чем взрослые. Кроме того, современную информационную культуру можно назвать также кофигуративной (термин М. Мид), то есть, культурой, в которой преобладают модели поведения, соответствующие стремительно развивающемуся обществу. Это модели поведения, в которых взрослые учатся у детей, дети учатся у взрослых; и те, и другие - учатся у сверстников, принимая во внимание их ошибки и способы достижения успеха. М. Мид отмечала также, что кофигуративной культуре свойственен конфликт поколений, порождаемый неидентичностью типичных форм поведения представителей разных поколений. Эти конфликты, согласно Мид, обостряются, когда взрослеющие дети не придерживаются (в силу свойств стремительно меняющегося пространства, вызывающего к жизни новые стратегии поведения) тех жизненных стандартов и поведенческих стратегий, которым обучали их родители в процессе воспитания.

Мы, в свою очередь, предлагаем ввести термин "метафигуративности", который, по нашему мнению, лучше соответствует характеру современного общества (мы называем его, вслед за П. Пискаревым [6], обществом метамодерна). Общество метамодерна предполагает одновременное существование разных социальных, культурных образцов; она похожа (метафорически) на "многоквартирный дом", в котором гармонично и бесконфликтно живут совершенно разные семьи: представители разных поколений, культур, ценностей, придерживающиеся разных моделей развития семьи и т.д. По сути, внутри каждой такой семьи формируется собственное когнитивно-коммуникативное пространство, сформированное по ряду аспектов взаимодействия внутри этого пространства. Аспекты когнитивно-коммуникативного взаимодействия: финансовый, аспект личных взаимоотношений, корпоративный (в данном случае семью можно рассматривать как своего рода корпорацию), проектный (семейные проекты), собственно семейный (взаимоотношения внутри своей семьи и с родительскими семьями), телесный (телесный контакт, здоровье членов семьи), психологический (психологический климат семьи), образовательный (семья как образовательная и воспитательная среда), религиозный (отношение семьи к религии), национальный, культурный, ценностно-нормативный (ценности и нормы, исповедуемые и соблюдаемые семьей и ее членами) и т.д.

В соответствии с написанным выше, сформируем "рамку", “фрейм", основанный на парадигме М. Мид, а также на методологии П. Пискарева [6 c.17], который предполагает рассматривать теории через концептуально-аналитическую призму четырех квадрантов, где первый соответствует премодерну (как традиционной, наиболее древней эпохе становления человечества и человека, доиндустриальному этапу развития общества), второй - модерну (как эпохе интенсивного развития науки, географических открытий, началу формирования индустриального общества, существования сословного общества), третий - постмодерну (как эпохе развития индустриального общества и капитализма, классового общества, интенсивного развития индустриальной техники и технологий), четвертый - метамодерну (современной эпохе развития человечества, где традиционные классы и сословия, а также традиционные возрастные рамки размываются, общество входит в этап постиндустриального развития, интенсивного формирования и трансформации информационной среды и т.д.).

С этой точки зрения, структурные элементы парадигмы М. Мид так ложатся в четырехкомпонентную рамку (Таб. 1.). 
Таблица 1.

Парадигма культур М.Мид через призму четырехкомпонентной рамки ("теория метамодерна")

\begin{tabular}{|l|l|}
\hline Метамодерн & Премодерн \\
Метафигуративная культура & Постфигуративная культура \\
\hline Постмодерн & Модерн \\
Кофигуративная культура & Префигуративная культура \\
\hline
\end{tabular}

Обратимся к межпоколенному аспекту в контексте интегрального образования. По нашему мнению, заявленная тема связана с межпоколенным аспектом социального взаимодействия. Межпоколенный аспект социального взаимодействия, а также межпоколенная коммуникация как отдельный аспект межпоколенного взаимодействия, рассмотрены в ряде работ зарубежных и отечественных авторов. Так, проблемами межпоколенного взаимодействия занимались такие известные зарубежные авторы, как М. Мид, С.Н. Паркинсон, С.И. Голод, В.Ж. Келле, и др. Коммуникативный аспект межпоколенного взаимодействия рассматривали также отечественные ученые, среди которых А.Г. Асмолов, Л.С. Выготский, Е.И. Рассказова, М.В. Сапоровская. Проблема коммуникации разрабатывалась в руслах различных наук: социологии, психологии, культурологии, филологии и лингвистики, философии, политологии и т.д. В рамках социологии (на стыке с психологией и философией) теория коммуникации развивалась в экзистенциализме, бихевиоризме, необихевиоризме, феноменологии, структурно-функциональном анализе, социологии повседневности (теория фреймов) и т.д.

Нам представляется интересным, среди прочего, направление символического интеракционизма в контексте изучения межпоколенного взаимодействия. В теоретической концепции символического интеракционизма выделяются социальные факторы, обуславливающие человеческое поведение. Так как по мнению интеракционистов социализация в своем базисе выстроена на способности общения между индивидами и совершенствовании этой способности в социальном взаимодействии на протяжении всей жизни человека, особенно важным в коммуникации (интеракции) является достижение взаимопонимания между поколениями (старшее и молодое).

Н.Г. Горбачева в исследовании символического интеракционизма в контексте межпоколенной коммуникации подчеркивает значимость «взаимодействия, в ходе которого и осуществляется формирование поведения личности. Все формы социального взаимодействия в обществе, характерные данному направлению, подразумевают общение, основывающиеся на определенных социальных символах - языке, телодвижениях, жестах, культурных и других символах. Таким образом, межпоколенная коммуникация понимается как интерпретация поведения людей, которое основывается на символах, несущих социальную информацию» [2].

Символический интеракционизм как аспект социального взаимодействия, основанный на определенном символическом "фундаменте", представляется особенно важным в контексте проблем современного интегрального образования, в частности - межпоколенного взаимодействия в рамках интегрального образования. Так, современная коммуникация несет значительную символическую (ценностно-символическую) нагрузку. Символы, значимые для молодого поколения (например, поколения учеников) ранее могли не узнаваться и не разделяться старшим поколением (например, поколением учителей и родителей). Сегодня символический интеракционизм проявляется не только в межпоколенном, но и в кросспоколенном взаимодействии, где среди учеников находим представителей разных поколений, а также - внутри групп учителей и родителей также непрерывно коммуницируют представители разных поколений (выше мы писали, что родители учеников одного возраста могут относиться к разным поколениям). В контексте доктрины символического интеракционизма особенно важен информационный аспект: так, многие люди сегодня взаимодействуют в рамках интернет-пространств, изобилующих схожими (или одними и теми же символами). В этом смысле, сегодня есть все возможности для преодоления символического (ценностно-символического) разрыва поколений.

С точки зрения ценностей интегрального образования, "символический разрыв", существующий у представителей разных поколений, не только должен преодолеваться, но также должен рассматриваться по-другому. Так, мы должны смотреть на условную группу "учеников" не как на представителей некоторого поколения, у которого якобы существуют единые, известные нам "символы”, “ценности", характерные ментальностные особенности, а как на интегральное пространство единства уникальных личностей, каждая из которых может обладать своим собственным набором ценностей, символов и т.д. Мы полагаем, что попытки анализа той или иной группы (в рамках образовательного пространства) с точки зрения ее гомогенности и "символического, "ментальностного" единства заранее обречены на неуспех. Кроме того, попытки понимания коллектива учеников, преподавателей, группы родителей как носителей однородных целей и ценностей всегда будут ошибочными (даже если это понимание принадлежит учителю, взаимодействующему как с учениками, так и с родителями).

Еще один значимый аспект, нивелирующий негативные проявления межпоколенной интеракции в интегральном образовании, - это то, что коллектив учеников, учителей и родителей в интегральном образовании действует в рамках единого коммуникативного топоса, 
где нет "главных" и "второстепенных" акторов, где учитываются особенности личности каждого участника процесса. Можно вспомнить традиции советских школ, где основной упор делался не столько на коллективное взаимодействие, сколько на коллектив как основную социальную ценность. Личность в коллективе была менее важна, чем коллектив в целом, главенствовало убеждение, что "незаменимых людей нет", и т.д. В концепции интегрального образования коллективное взаимодействие также важно, но оно представляет собой уникальное пространство интеракции неповторимых и незаменимых личностей. По нашему мнению, установкой интегрального образования может быть утверждение "каждый - незаменим".

Ключевой принцип интегрального образования - в том, что личность каждого участника образовательного процесса, будь то ученик, преподаватель (учитель) или родитель, - важна, как важны и ценности этой личности, ее взгляды, убеждения, символы, таланты.

Внутренняя структура образовательных пространств в рамках интегрального образования - подвижна и динамична. На смену привычной нам субординации, где старший - главнее, приходит "интегральная субординация" (авторский термин), где главными могут быть любые участники, в зависимости от целей конкретного проекта и взаимодействия в рамках этого проекта.

Межпоколенная коммуникация в интегральном образовании также не вертикальная, а, скорее, горизонтальная: все участники процесса равны, но при этом - уникальны; говоря о "равенстве”, мы имеем в виду взаимодействие на равных, а также равноценность мнений, которые может высказать каждый участник интегрального образовательного пространства и процесса. Отметим также, что "горизонтальность" межпоколенной интеракции, хоть и преобладает в процессе интегрального образования, все же существует в органическом единстве с элементами вертикальной интеракции, потому что, если вертикальная интеракция будет отсутствовать вообще, это, возможно, негативно отразится на качестве учебного процесса (будет невозможна отчетность, будут нарушаться дедлайны, пострадают психологические границы участников и т.д.). Таким образом, о коммуникативном процессе в интегральном образовании можно говорить как о смешанном, с преобладанием горизонтальных интеракций, а также при наличии вертикальных интеракций. Очень важно, по нашему мнению, соблюдение балансного соотношения "вертикальных" и "горизонтальных" элементов. Это соблюдение возможно при условии того, что большинство участников образовательного процесса разделяет общие ценности, а также действует в одном нормативном поле учебного процесса, участники которого договорились о соблюдении определенных норм и правил, близких им всем.
Формирование и установление интегрального ценностно-нормативного пространства, таким образом, можно назвать одним из фундаментальных условий успешного интегрального образования.

Итак, мы можем сделать следующие выводы:

1. Образование личности мы называем интегральным образованием и понимаем под ним процесс, непрерывный по ряду значимых параметров: во времени (образование в течение всей жизни и на протяжении каждого конкретного дня), в пространстве (в том числе - в реальном и интернетпространствах), в межличностном и внутриличностном аспектах (то есть, в поле межличностной и внутриличностной коммуникации). Мы называем такой процесс интегральным, а такой (образовательный) феномен - интегральным образованием.

2. Мы говорим о непрерывном образовании личности, то есть, о преемственности этапов ее образования, а также об образовании на протяжении всей ее жизни, в интегральном единстве различных сфер ее жизни, а также отдельных ролей ее ролевого репертуара.

3. Мы выделяем такие значимые аспекты интегральности (интегрального образования): первый смешение контекстов ("учебного" и "домашнего", "частного" и "публичного"); второй - интеграция виртуального и реального пространств коммуникации, третий - смешение, объединение ролей участников образовательного процесса.

4. В современном "удаленном" образовании, связанном с пандемией, ролевой репертуар родителя принудительно "обогащается" новыми ролями, среди которых - роли тьюторов, психологов, воспитателей, техподдержки, репетитора, “домашнего преподавателя" и т.д. Этот аспект смешения ролей имеет отношение не к парадигме интегрального образования, а к практике домашнего "удаленного" обучения в том виде, в котором оно сейчас существует.

5. Мы полагаем, что родители в интегральном образовании должны стать полноценными участниками образовательного процесса, но не как“домашние учителя", а как люди, имеющие представление о том, что происходит в образовательном пространстве, и способные, наравне с преподавателями и учениками, иметь и высказывать мнение о том, как это пространство должно развиваться. Родители, учащиеся и преподаватели должны взаимодействовать в едином (интегральном) пространстве коммуникации.

6. Образовательный процесс в интегральном образовании должен проходить в интегративной обстановке, которая создает такую атмосферу (пространство), где усвоение, запоминание, пони- 
мание дисциплины (предмета) легче, поскольку нет робости и стресса, сопутствующих привычной образовательной среде, существующей сегодня, где правота учителя несомненна, а правоту ученика еще нужно доказать, и роли, отведенные каждому из участников, не имеют таких жестких и подавляющих ограничений и рамок, как при вертикальной иерархичной коммуникации.

7. Мы рассматриваем концепцию взаимодействия культур М. Мид, описанную ею в книге "Культура и мир детства". Мы трактуем подход М. Мид к пониманию культур - постфигуративной, префигуративной, кофигуративной через призму четырехкомпонентной модели, разработанной П. Пискаревым. Рассматривая межпоколенное взаимодействие в контексте концепции М. Мид, мы предлагаем авторский термин "метафигуративная культура", соответствующий современному (метамодерному) состоянию общества. Метафи- гуративная культура схожа с кофигуративной в том, что предусматривает обучение как старших у младших, так и младших у старших, а также представителей всех поколений - у своих ровесников. Отличает метафигуративную культуру одновременное сосуществование разных культурных образцов, сохранение элементов префигуративной и постфигуративной культуры "в чистом виде" в рамках одного общества, признание и уважение к разным культурным образцам, не противоречащим принципам гуманизма. Также метафигуративной культуре свойственна не межкультурная, а кросскультурная (не межпоколенная, а кросспоколенная) коммуникация, где представители разных поколений и культур взаимодействуют одновременно в одном когнитивно-коммуникативном пространстве, формируя его неповторимый характер.

\section{ЛИТЕРАТУРА}

1. Ассаджиоли Р. Психосинтез: принципы и техники. - М: Институт Общегуманитарных Исследований. - 2016. - 204 с.

2. Горбачева Н.Г Межпоколенная коммуникация сквозь призму символического интеракционизма. // Азимут научных исследований: педагогика и психология. № 1(10) - 2015. - С. 61-64.

3. Лапидус Н.А. "Слэш-люди": методы выявления мультипотенциалов с помощью инструментов метамодерна // Человеческий фактор: социальный психолог. - 2020. - № 1(39). - С.363

4. Мид М. Культура и мир детства. Избранные произведения. Пер. с англ. и коммент. Ю.А. Асеева. Сост. и послесловие И.С. Кона. - М: Главная редакция восточной литературы издательства“Наука”, 1988. - 429 с.

5. Непомнящий А. В. Интегральное образование. научное изд., М.: Изд-во ЮФу, 2016. - 98с.

6. Пискарев П.М. Метамодерн и интегративная теория гуманитарного знания: дис. ... Д-ра психол.наук. — Яр., 2019 — С.346-358

7. Стоун Х. Уинкельман С. Принимая собственные «я»: Руководство по Диалогу голосов / Пер. с англ. А. Бойкова, А. Костровой. — М.: Изд-во Эксмо; СПб.: Домино, 2003. - 304 c.

8. Фуко М. Око власти // Фуко М. Интеллектуалы и власть: избранные политические статьи, выступления и интервью. М.: Праксис, 2002. С. 224

9. Фуко М. Пространство, знание, власть // Фуко М. Интеллектуалы и власть: избранные политические статьи, выступления и интервью. М.: Праксис, 2006. 4. 3.320 c.

10. Шварц Р. К. Системная семейная терапия субличностей. М: Научный мир. - 2011. - 336 с.

11. Юнг К.Г. Психологические типы. - М: «Университетская книга» - Изд. АСТ, - 1998. - 720с.

12. Bowen, M. (1978). Family Therapy in Clinical Practice. New York: Jason Aronson. 